\title{
Catch-22: Management of aortoesophageal fistula after thoracic endovascular aortic repair
}

\author{
John S. Ikonomidis, MD, PhD
}

\author{
From the Division of Cardiothoracic Surgery, University of North Carolina at Chapel Hill, Chapel Hill, NC. \\ Disclosures: Author has nothing to disclose with regard to commercial support. \\ Received for publication May 21, 2017; accepted for publication May 23, 2017; available ahead of print June 22, \\ 2017. \\ Address for reprints: John S. Ikonomidis, MD, PhD, Division of Cardiothoracic Surgery, University of North Car- \\ olina at Chapel Hill, 3034 Burnett-Womack Bldg, 160 Dental Cir, Chapel Hill, NC 27599-7065 (E-mail: \\ john_ikonomidis@med.unc.edu). \\ J Thorac Cardiovasc Surg 2017; 154:787 \\ $0022-5223 / \$ 36.00$ \\ Copyright (C) 2017 by The American Association for Thoracic Surgery \\ http://dx.doi.org/10.1016/j.jtcvs.2017.05.082
}

Fernandez and colleagues ${ }^{1}$ describe an aortoesophageal fistula in a 78-year-old woman who presented with hematemesis 2.5 years after thoracic endovascular aortic repair (TEVAR). Work-up demonstrated a type 1A endoleak and a large necrotic esophageal ulcer. The patient underwent proximal endograft extension after carotid-carotid bypass as well as placement of an esophageal stent. The patient refused interval esophagectomy with retrosternal gastric reconstruction, and at the time of the report (6 months after the procedure) was symptom free and taking antibiotics.

Of the potential complications associated with TEVAR, perhaps none are more devastating than aortobronchial and aortoesophageal fistulae. The latter complicates about $2 \%$ of TEVAR cases and can occur in patients with rupture, dissection, or aneurysm. ${ }^{2}$ The mechanism of formation may be multifactorial and involve deprivation of the esophageal blood supply due to coverage by the stent graft, erosion of the stent graft through the aorta (especially if the device collapses), stent graft infection, ongoing endoleak, and pressure imposed on the esophageal wall as the stent graft expands. ${ }^{2}$ Presentation is typically sepsis or varying degrees of hematemesis. Laboratory testing may show elevated white blood cell, C-reactive protein, fibrinogen, and Ddimer values. ${ }^{2}$ The diagnosis is made with either computed tomography or magnetic resonance imaging and an upper endoscopy.

Treatment of these patients is very challenging due to the anatomic location of the fistula, and (usually) the presence of an infected field. Most reports have found that management with repeat TEVAR extensions, esophageal stent grafting, and long-term antibiotics more often than not result in death from recurrent bleeding or sepsis. ${ }^{2-4}$ Definitive management usually involves open esophagectomy and/or segmental aortic replacement, ${ }^{5,6}$ but this strategy is often limited by the poor baseline health of the patient and even if successful, may not be adequate treatment.

The patient described by Fernandez and colleagues ${ }^{1}$ refused definitive surgery and hence remains at

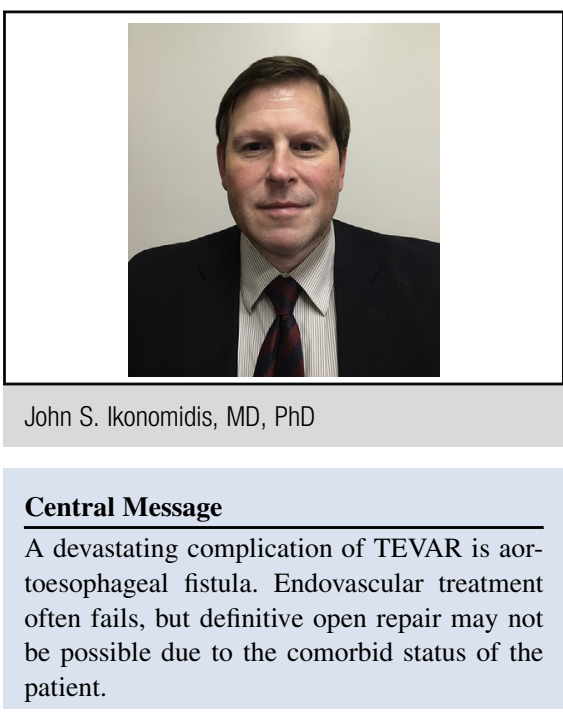

See Article page 785 .

significant risk for a catastrophic outcome. Endovascular specialists must be constantly mindful of the potential for this devastating complication in their patients. Unfortunately, the ultimate therapy is challenged by a catch-22: The potential inadequacy of an endovascular solution and the morbidity associated with extensive open surgical repair.

\section{References}

1. Fernandez R, Malaisrie SC, Hoel A, Bharat A. Aortoesophageal fistula resulting from aortic endograft migration. J Thorac Cardiovasc Surg. 2017; 154: 785-6.

2. Heggbrecht H, Mehta RH, Dechene A, Tsagakis K, Kuhl H, Huptas S, et al. Aortoesophageal fistula after thoracic aortic stent graft placement. A rare but catastrophic complication of a novel emerging technique. JACC Cardiovasc Interv. 2009:2:570-6.

3. Yavuz S, Kanko M, Ciftci E, Parlar H, Agirbas H, Berki T. Aortoesophageal fistula secondary to thoracic endovascular aortic repair of a descending aortic aneurysm rupture. Heart Surg Forum. 2011;14:E249-51.

4. Ferrero E, Viazzo A, Ferri M, Rocca R, Pecchio A, Piazza S, et al. Acute management of aortoesophageal fistula and tracheoesophageal fistula treated by thoracic endovascular aortic repair and esophageal endoprosthesis: a case misdiagnosed as esophageal cancer. Ann Vasc Surg. 2011;25:1142.

5. Cheng L, Zhu J, Liu X, Liu W, Hu H, Zhang J, et al. A successful threestage surgical treatment for aortoesophageal fistula after thoracic endovascular aortic repair and esophageal stent repair. Ann Thorac Surg. 2016;102: e503-5.

6. Chiba D, Hanabata N, Araki Y, Sawaya M, Yoshimura T, Aoki M, et al. Aortoe sophageal fistula after thoracic endovascular aortic repair diagnosed and followed with endoscopy. Intern Med. 2013;52:451-5.

7. Seto T, Fukui D, Tanaka H, Komatsu K, Ohtsu Y, Terasaki T, et al. Tracheo-bronchial obstruction and esophageal perforation after TEVAR for thoracic aortic rupture. Ann Vasc Dis. 2014;7:421-5. 